\title{
Reforma agrária em questão (Banco de dados da luta pela terra - DATALUTA)
}

Agrarian reform in question (Database for the fight for land - DATALUTA)

Reforma agraria en cuestión (Base de datos para la lucha por la tierra - DATALUTA)

\author{
João Cleps Junior ${ }^{1}$ \\ Fabiana Borges Victor ${ }^{2}$ \\ Cairo Roberto Boaventura Júnior ${ }^{3}$ \\ Karen Regina Silva Costa ${ }^{4}$
}

\begin{abstract}
RESUMO: Este relato apresenta as experiências resultantes da proposição e do desenvolvimento de uma roda de conversa sobre a realidade agrária brasileira na perspectiva do Banco de Dados da Luta pela Terra (DATALUTA). A intervenção integrou a V Jornada Universitária em Defesa da Reforma Agrária, realizada na Universidade Federal de Uberlândia em maio de 2019, e se configurou como um importante instrumento metodológico em que foram expostos os conhecimentos em um momento de construção coletiva de reflexões a partir das vivências e saberes dos participantes.
\end{abstract}

Palavras-chave: Roda de conversa. Questão agrária. Jornada Universitária em Defesa da Reforma Agrária (JURA). Banco de Dados da Luta pela Terra (DATALUTA).

\begin{abstract}
This report presents the experiences resulting from the proposition and development of a conversation circle about the Brazilian agrarian reality from the perspective of the Database of the Struggle for the Land (DATALUTA). The intervention was an integral part of the 5th University Journey in Defense of Land Reform held at the Federal University of Uberlândia, in May 2019, and was configured as an important methodological instrument in which the knowledge was exposed in a moment of collective construction of reflections from the participants' experiences and knowledge.
\end{abstract}

Keywords: Conversation circle. Agrarian question. University Journey in Defense of Agrarian Reform (JURA). Land Struggle Database (DATALUTA).

RESUMEN: Este informe presenta las experiencias como resultado de la propuesta y el desarrollo de una rueda de conversación sobre la realidad agraria brasileña desde la perspectiva de la Base de datos de Lucha por La Tierra (DATALUTA). La intervención fue parte de la V Jornada Universitaria en Defensa de la Reforma Agraria celebrada en la

\footnotetext{
${ }^{1}$ Doutor em Geografia pela Universidade Estadual Paulista Júlio de Mesquita Filho, Campus Rio Claro, São Paulo, Brasil; professor titular do Instituto de Geografia da Universidade Federal de Uberlândia, Minas Gerais, Brasil; coordenador do Laboratório de Geografia Agrária (LAGEA) e do Núcleo de Estudos Agrários e Territoriais (NEAT); membro pesquisador do Núcleo de Estudos, Pesquisas e Projetos de Reforma Agrária (NERA-Unesp) e da Rede de Pesquisa DATALUTA (jcleps@ufu.br).

${ }^{2}$ Mestre em Geografia pela Universidade Federal de Uberlândia, Minas Gerais, Brasil; pesquisadora do Núcleo de Estudos Agrários e Territoriais (NEAT); colaboradora do Projeto Banco de Dados da Luta pela Terra (DATALUTA); professora de Geografia na rede estadual de educação em Uberlândia, Minas Gerais, Brasil (fabianabvictor@yahoo.com.br).

${ }^{3}$ Graduando em Geografia na Universidade Federal de Uberlândia, Minas Gerais, Brasil; membro bolsista CNPq do Laboratório de Geografia Agrária (LAGEA) (boav.cairo@gmail.com).

${ }^{4}$ Graduanda em Geografia na Universidade Federal de Uberlândia, Minas Gerais, Brasil; bolsista no projeto de extensão "Plantando liberdade para além das grades: um projeto de hortas e jardins para mulheres encarceradas" (karenrege@ hotmail.com).
} 
Universidad Federal de Uberlândia, en mayo de 2019, configurándose como una herramienta metodológica importante a partir de la cual se expuso el conocimiento en un momento de construcción colectiva de reflexiones a partir de experiencias y conocimientos de los participantes.

Palabras clave: Rueda de conversación. Cuestión agraria. Jornada Universitaria en Defensa de la Reforma Agraria (JURA). Base de datos de Lucha por la Tierra (DATALUTA).

\section{INTRODUÇÃO}

A formação territorial brasileira historicamente implica nas lutas pela terra. $\mathrm{Na}$ atual conjuntura do país, se faz necessária a discussão sobre essas lutas, assim como de que forma os movimentos sociais as articulam no território, e também de que maneira estão sendo noticiadas pelas mídias e recebidas pelo público.

A Roda de Conversa sobre o Banco de Dados da Luta pela Terra (DATALUTA) foi realizada como parte da V Jornada Universitária em Defesa da Reforma Agrária (JURA), juntamente com diversas atividades da UFU e principalmente em âmbito do $9^{\circ}$ Simpósio Internacional: O Estado e as Políticas Educacionais no Tempo Presente e da VII Feira Regional de Economia Popular Solidária. A Roda de Conversa é uma ferramenta pedagógica coletiva de construção e aplicação de conhecimentos, tendo como protagonistas as trabalhadoras e trabalhadores na sugestão e discussão de temas relevantes. Nesse espaço, os sujeitos discutem sua realidade; compartilham experiências; ouvem e são ouvidos. Além disso, podem refletir para agir coletivamente, buscando influenciar e transformar o meio em que vivem.

A Roda de Conversa foi pensada pelos pesquisadores do Laboratório de Geografia Agrária (LAGEA), da Universidade Federal de Uberlândia (UFU), com a finalidade de trazer a metodologia de construção do Banco de Dados da Luta pela Terra (DATALUTA) e mostrar exemplos de estudos que podem e fazem uso dessas informações, a partir de abordagens temáticas mais relevantes da questão agrária brasileira e, principalmente, da Reforma Agrária.

A escolha do projeto de extensão e pesquisa, apoiado pela PROEXC-UFU desde 2008 e mais recentemente pela PROEXT da UFTM a partir de 2015, deve sua importância institucional e social com os levantamentos e estudos difundidos para a comunidade científica e organizações públicas e sociais envolvidas com a temática de DESENVOLVIMENTO TERRITORIAL, DIREITOS HUMANOS e QUESTÃO AGRÁRIA. A proposta pauta-se no registro e na divulgação da luta pela terra, em especial no Estado de Minas Gerais, enfatizando a atuação dos movimentos socioterritoriais, por meio dos conflitos agrários. 
Os dados pesquisados e divulgados pelo DATALUTA são referentes às ocupações, manifestações, movimentos socioterritoriais, assentamentos rurais e estrutura fundiária, além de estrangeirização da terra. Esses dados são coletados e sistematizados mensalmente para envio ao setor de documentação da CPT/Nacional (Centro de Documentação Dom Tomás Balduino), entidade ligada à Igreja Católica surgida em 1975, para serem publicados anualmente no Caderno Conflitos no Campo Brasil ${ }^{5}$ e nos Relatório da REDE DATALUTA 6 .

Nos últimos quatro anos (2015-2019), o LAGEA, juntamente com seus parceiros internos e externos, promoveram a Jornada Universitária em Defesa da Reforma Agrária (JURA), evento organizado entre os movimentos sociais e universidades brasileiras, oportunidade em que também são divulgados os resultados do projeto em escala nacional, estadual e regional. Assim, envolveu uma proposta com ações práticas e relevantes de socialização do conhecimento acumulado nos últimos anos, via produção de banco de dados, para as principais organizações do país envolvidas com a questão agrária brasileira, escolas e comunidades de assentados da Reforma Agrária.

\section{DATALUTA: histórico das pesquisas e temas de estudos}

O DATALUTA é um projeto de extensão e pesquisa criado em 1998 no Núcleo de Estudos, Pesquisas e Projetos de Reforma Agrária (NERA), vinculado ao Departamento de Geografia da Faculdade de Ciências e Tecnologia da Universidade Estadual Paulista (UNESP), campus Presidente Prudente. Em 2005, o projeto foi criado em Minas Gerais, por meio do Convênio de Cooperação entre a UFU e a UNESP. Assim, os dados e informações mensalmente sistematizados são ferramentas legítimas e importantes para a consulta pelos diferentes agentes sociais para entendimento da questão agrária nacional e em escala estadual.

\footnotetext{
${ }^{5}$ https://www.cptnacional.org.br/component/jdownloads/category/41-conflitos-no-campo-brasil-publicacao? Itemid $=0$.

${ }^{6} \mathrm{http}: / /$ www.lagea.ig.ufu.br/relatoriosdatalutaminas.html.
} 
Figura 1 - Espacialização da Rede DATALUTA de pesquisa no Brasil (2018)

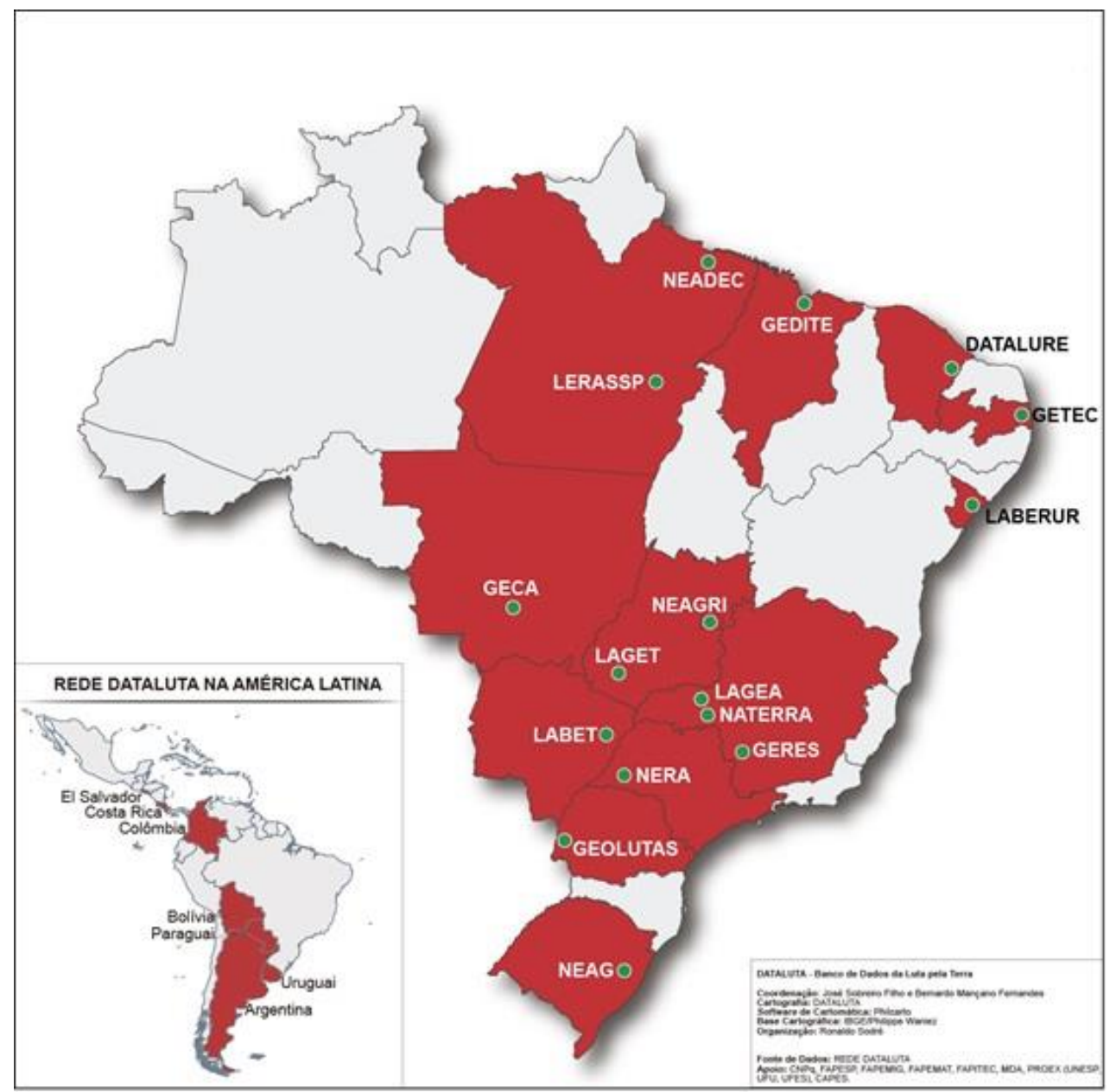

Fonte: DATALUTA (2019) / www.fct.unesp.br.

No sentido de propiciar leituras diversas desse contexto, os pesquisadores criaram um coletivo de pensamento, a REDE DATALUTA (Figura 1), agregando esforços, concentração e disciplina de doze grupos de pesquisas das seguintes universidades: NERA-UNESP; LAGEA-UFU; Núcleo de Estudos Territoriais e Agrários (NaTERRA), Universidade Federal do Triângulo Mineiro (UFTM); Laboratório de Geografia das Lutas no Campo e na Cidade (GEOLUTAS) da Universidade Estadual do Oeste do Paraná (UNIOESTE), campus de Marechal Rondon; Núcleo de Estudos Agrários (NEAG) do Departamento de Geografia da Universidade Federal do Rio Grande do Sul (UFRGS); Grupo de Pesquisas em Geografia Agrária e Conservação da Biodiversidade do Pantanal (GECA) da Universidade Federal de Mato Grosso (UFMT); Laboratório de Estudos Rurais e Urbanos (LABERUR) do Departamento de Geografia da Universidade Federal do Sergipe (UFS); Grupo de Estudos sobre Trabalho, Espaço e Campesinato (GETEC) da Universidade Federal da Paraíba 
(UFPB); Laboratório de Estudos Territoriais (LABET) da Universidade Federal do Mato Grosso do Sul (UFMS), campus de Três Lagoas; o Núcleo de Estudos e Pesquisas Agrárias sobre Desenvolvimento, Espaço e Conflitualidades (NEADEC) da Universidade Federal do Pará (UFPA); e o Laboratório de Estudos Regionais e Agrários no Sul e Sudeste do Pará (LERASSP) da Universidade Federal do Sul e Sudeste do Pará (Unifesspa). Essa articulação de grupos de pesquisa contribui para a espacialização do DATALUTA, criando condições de estabelecer uma rede nacional com obtenção de dados mais apurados, auxiliando para a qualificação do conhecimento e no desenvolvimento dos temas vinculados à questão agrária.

A metodologia do banco de dados DATALUTA consiste na coleta, sistematização, análise e divulgação de dados sobre o campo brasileiro a partir das categorias representadas no Organograma 1, a seguir:

Organograma 1 - DATALUTA: escalas, categorias e fontes de dados

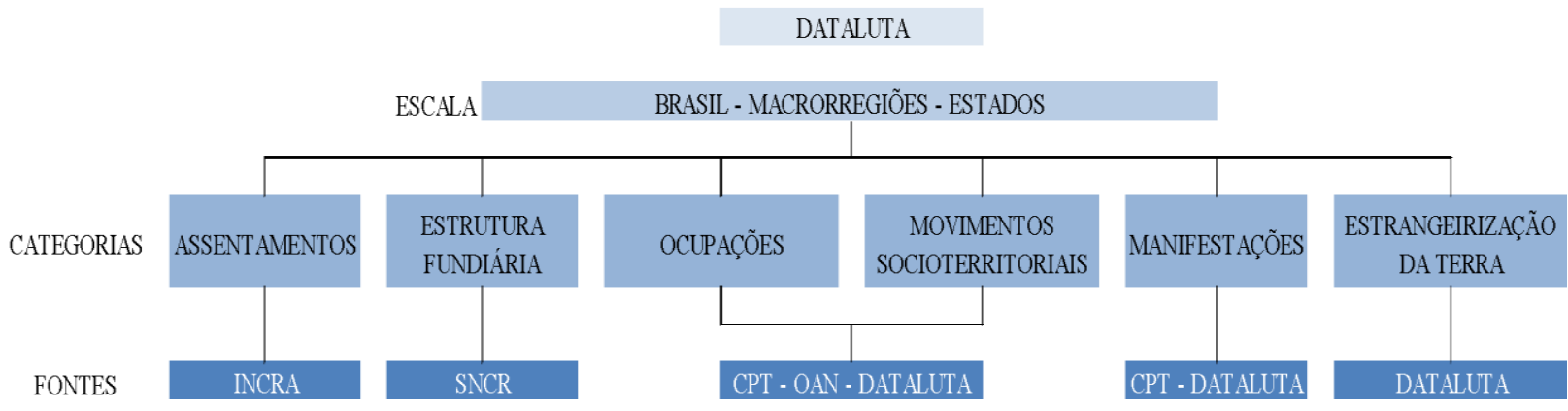

Fonte: DATALUTA (2019) / www.fct.unesp.br.

O LAGEA é responsável pela coleta e conferência de dados em jornais impressos e digitais de Minas Gerais e também por sistematizar mensalmente os registros dos demais estados/grupos da Rede Dataluta para envio à Comissão Pastoral da Terra (CPT). Ao final de cada ano, os dados são agrupados e confrontados para evitar a duplicidade de informações, gerando assim um único banco de dados, mais amplo, nacional e completo.

A organização desses dados subsidia uma análise aprofundada de como a luta pela terra vem se espacializando pelo Brasil. O primeiro relatório é de 1999 e, até 2002, foi publicado nas versões ocupações e assentamentos em escalas nacional, macrorregional, estadual, microrregional e municipal. Nos anos de 2003 e 2004, foram incorporadas as versões estrutura fundiária e movimentos socioterritoriais. Em 2009, foi iniciada a sistematização e análise da categoria manifestações. 
O princípio fundamental que guia o desenvolvimento do DATALUTA como projeto de pesquisa e extensão é o entendimento da necessidade e do dever da universidade na promoção, subsídio e participação do debate sobre a questão agrária no Brasil, compreendendo que esse é um tema fundamental para o desenvolvimento do país. Os dados e análises são fornecidos para cursos de extensão junto a comunidades rurais em todo o Brasil por meio dos membros da Rede.

Ao tratar a reforma agrária, luta pela terra e movimentos socioterritoriais, o DATALUTA está alicerçado no Paradigma da Questão Agrária (PQA), que enfatiza os problemas causados no campo pelo desenvolvimento do capitalismo (FELÍCIO, 2011; FERNANDES, 2005). São obras referenciais as de Kautsky (1986), Chayanov (1974) e Lênin (1982), que estudaram esse processo na Europa no período de desenvolvimento do capitalismo no campo naquela região. Os processos verificados por esses autores ainda podem ser observados no mundo todo na atualidade, com as devidas atualizações da dinâmica desse sistema. A questão central da diferenciação, empobrecimento e desintegração do campesinato ainda é o centro da questão agrária.

Para entender esse processo no período atual com vistas à proposição de alternativas que promovam o desenvolvimento do campo, vários autores dessa linha embasam a discussão, assim como também há o debate com autores contrários a esse paradigma, o que possibilita o avanço da ciência. Autores contemporâneos referenciais para o DATALUTA são Theodor Shanin, José de Souza Martins, Miguel Altieri, Henry Bernstein, Bernardo Mançano Fernandes, Ariovaldo Umbelino de Oliveira, Carlos Walter Porto-Gonçalves. A partir desses referenciais tem-se como foco de análise a luta pela terra no Brasil, compreendendo que esse processo é responsável pelas conquistas de alteração da estrutura agrária brasileira nas últimas décadas, e fundamental para a promoção do desenvolvimento no campo.

Os indicadores empregados podem ser agrupados em duas categorias: quantitativos e qualitativos. Os indicadores quantitativos consistem na coleta, sistematização e tabulação dos dados relacionados à luta pela terra: ocupações de terra, assentamentos rurais, movimentos socioterritoriais, estrutura fundiária, manifestações e estrangeirização de terras. Para isso, são captadas notícias de fontes jornalísticas do estado de Minas Gerais, e ao término do ano os dados coletados de todos os grupos de pesquisa formam o relatório anual. Esses indicadores quantitativos possibilitam que os indicadores qualitativos sejam incorporados, e referem-se ao 
tratamento, análise e debate desses dados por meio de sua socialização com a comunidade, movimentos sociais, Estado e universidade.

O DATALUTA tem fornecido dados e análises de conjuntura agrária para academia, governo e movimentos sociais, pois, por meio de entrevistas e matérias e vários veículos, debates e colóquios, procedemos com a difusão, socialização e democratização do conhecimento à comunidade, efetivando a discussão e ações para a solução do problema agrário no Brasil, cumprindo com mais um dos objetivos sociais da Universidade pública. Ainda, as relações bilaterais, sobretudo com os movimentos sociais, são estarrecidas, aproximando comunidade e universidade. Com isso, o DATALUTA tem contribuído com o debate sobre a reforma agrária no Brasil, auxiliando no desenvolvimento de políticas públicas agrárias, bem como os próprios movimentos socioterritoriais nas suas reivindicações pelo acesso à terra e pela qualidade de vida, pautando o desenvolvimento do campo brasileiro.

Por sua difusão e utilização pelo governo, pela academia e pelos movimentos sociais, o DATALUTA tem sido importante no pensamento sobre a questão agrária brasileira e nas ações para o desenvolvimento do campo. Ressalta-se que a partir de 2009, o DATALUTA tornou-se um projeto da Cátedra UNESCO de Educação do Campo e Desenvolvimento Territorial. Atualmente o DATALUTA tornou-se uma referência nacional e internacional para os estudiosos da questão agrária, o que tem possibilitado intercâmbios de pesquisa com países como Canadá, Estados Unidos, Cuba, Espanha, Bolívia, Colômbia, Equador, Chile, Argentina, Uruguai e França.

Os principais resultados práticos da pesquisa DATALUTA, além da coleta, sistematização e envio para o Centro de Documentação Dom Tomás Balduino da CPT Nacional, outros produtos que se destacam em nível nacional e estadual são os Boletim Dataluta (mensal) e os relatórios anuais Dataluta Brasil e Dataluta Minas Gerais/Triângulo Mineiro, publicados anualmente. Os relatórios anuais do DATALUTA são entregues ao Acervo Documental do Movimento dos Trabalhadores Rurais Sem Terra (MST), estabelecido no Centro de Memória e Documentação (CEDEM), criado a partir de convênio celebrado entre a UNESP e a Associação Nacional de Cooperação Agrícola (ANCA). Também é disponibilizado nos sites do NERA: www.fct.unesp.br/nera, do LAGEA: www.ig.ufu.br/lagea e da Cátedra UNESCO de Educação do Campo e Desenvolvimento Territorial: www.unesp.br/educampo. Além disso, para a divulgação mais ágil dos dados do DATALUTA, em janeiro de 2008 foi criado o 
Boletim DATALUTA ${ }^{7}$. Com esse periódico são difundidas análises sobre as sistematizações e confrontações, bem como leituras de outros pesquisadores em publicação denominada “Artigo do Mês".

\section{O DATALUTA na V Jornada Universitária em Defesa da Reforma Agrária (JURA)}

A partir da aproximação dos sujeitos e movimentos sociais protagonistas da luta no campo, e acadêmicos, professores e pesquisadores que atuam nas instituições de ensino, em 2014 foi articulada a primeira edição da Jornada Universitária em Defesa da Reforma Agrária (JURA), deliberada no ano anterior durante o $2^{\circ}$ Encontro Nacional dos Professores Universitários e o MST, e definida para acontecer entre os meses de abril e maio "para dialogar com o dia 17 de abril, no qual o MST denuncia a impunidade do massacre de Eldorado dos Carajás, ocorrido nessa mesma data, em 1996, resultando na morte de 19 trabalhadores Sem Terra" (MST, 2018).

Trata-se não apenas de dar visibilidade ao processo de luta pela terra, mas principalmente às conquistas dos direitos sociais da classe trabalhadora do campo, fazendo com que seja cumprida a função social das universidades, que "afirmam o apoio à Reforma Agrária e à democratização da terra, reconhecem os movimentos sociais do campo como produtores de conhecimento e repudiam a sua criminalização, bem como reafirmam a necessidade de uma educação pública de qualidade" (MOURA; VICTOR; CLEPS JÚNIOR, 2015, p. 3).

As edições da JURA na UFU foram em 2014, 2015, 2016 e 2017. Em 2019, a V JURA foi realizada em conjunto com o $9^{\circ}$ Simpósio Internacional O Estado e as Políticas Educacionais no Tempo Presente e a VII Feira Regional de Economia Popular Solidária, no período de 8 a 10 de maio de 2019, e em parceria com a Universidade Federal do Triângulo Mineiro (UFTM). O encontro foi organizado conjuntamente com diversos movimentos e organizações sociais como a CPT, MLST, MPRA, MST, MINA e diversos coletivos constituídos por associações de agricultores, de trabalhadores e outros apoiadores, utilizando-se dos espaços na universidade enquanto uma instituição aberta à comunidade.

Quando estabelecida a ideia de uma roda de conversa com o tema da questão agrária a partir do projeto DATALUTA, o objetivo central foi promover um momento de diálogo e interação a fim de construir reflexões no que tange à realidade do espaço agrário brasileiro,

\footnotetext{
${ }^{7}$ www.fct.unesp.br/nera/boletim.
} 
compreendendo os conflitos e disputas, os sujeitos que reivindicam uma diversidade de direitos que garantam a vida e o trabalho no campo, as políticas públicas já conquistadas e as que ainda são necessárias. Soma-se a isso as experiências de cada participante que foram expostas durante a roda de conversa.

A atividade metodológica consistiu em três etapas: na primeira, foi disponibilizada a inscrição online dos participantes interessados na temática, visto que foram propostas rodas de conversa com temas variados e relacionados com os eventos acadêmicos já citados. Na segunda etapa, com o conhecimento prévio do número de inscritos, a atividade foi estruturada para ser desenvolvida em espaço aberto (praça do Bloco J) e próxima à feira que estava ocorrendo ao mesmo tempo, como pode ser identificada nas Fotos 1 e 2, considerando a possibilidade de surgirem novos participantes a partir desse momento de sociabilidade, e ainda com a intenção de dar visibilidade aos sujeitos da discussão. A terceira etapa foi de interação e diálogo, iniciado após uma breve exposição do assunto e continuado a partir das opiniões e posicionamentos de cada um. As intervenções durante a roda de conversa foram mediadas pelos pesquisadores do DATALUTA que traziam dados do contexto agrário à medida que as falas se desenvolviam.

Os pesquisadores do DATALUTA expuseram a dificuldade de se trabalhar com os dados advindos da mídia tradicional, que contribuem para desqualificar a luta pela terra. Mesmo na universidade, as pessoas têm se desinteressado pelos movimentos sociais, e assim, poucos pesquisadores embarcam na aventura de estudar e defender a reforma agrária. Em sua maioria, os participantes relataram as dificuldades enfrentadas na luta pela reforma agrária, o que será reproduzido adiante. 
Foto 1 - Rodas de Conversa ocorridas durante a V JURA e a Feira de Economia Popular Solidária na UFU (2019)

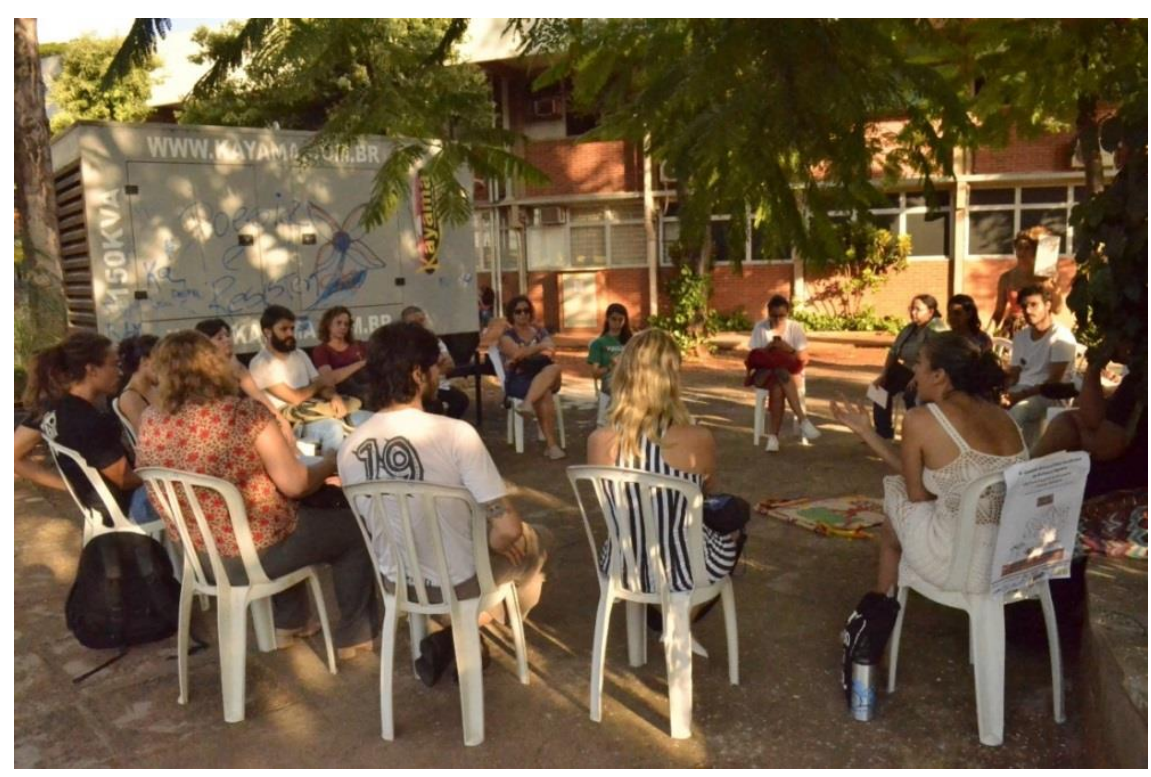

Foto: Brenda Rezende e João Vitor Martins Silva (2019).

Foto 2 - VII Feira Regional e V JURA (2019)

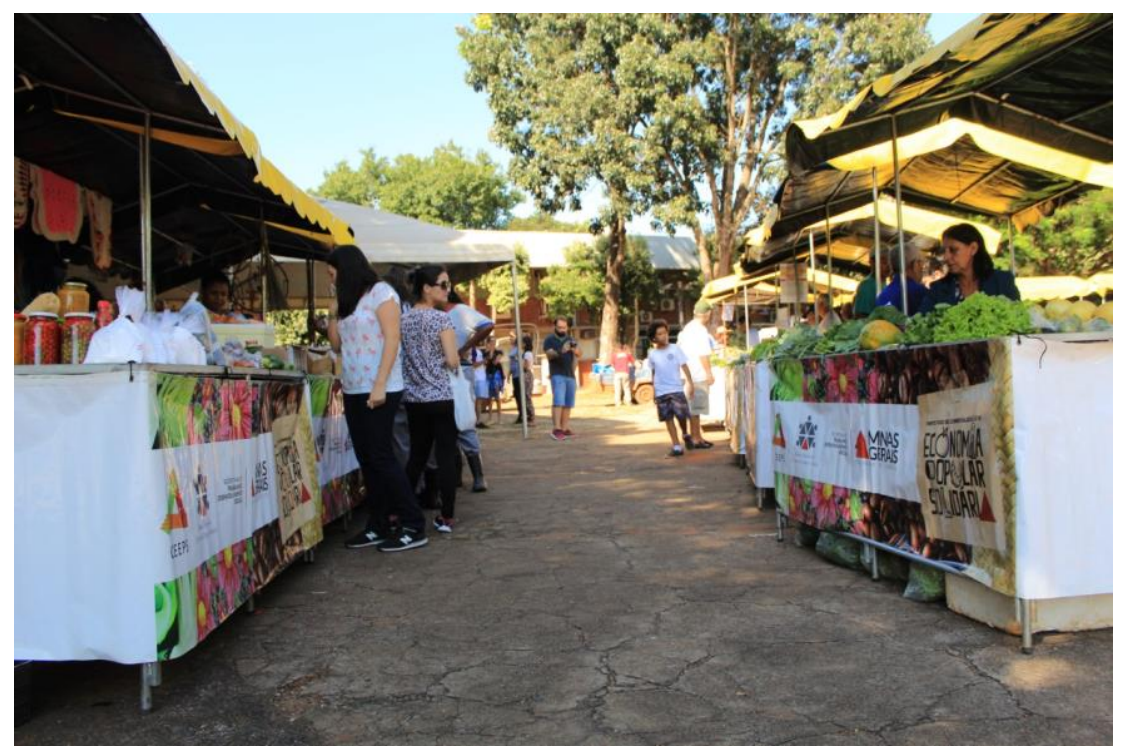

Fonte: Autores e pesquisadores do Dataluta (2019).

A falta de conhecimento gera preconceitos. A população em geral não conhece os movimentos sociais de luta pela terra. Nessa sociedade em que a propriedade privada é tratada como um domínio inquestionável, dificilmente as pessoas entendem ou procuram entender o motivo e a legitimidade de se lutar por uma terra que não cumpre sua função social, que de acordo com a Constituição Federal de 1988: 
Art. 186. A função social é cumprida quando a propriedade rural atende, simultaneamente, segundo critérios e graus de exigência estabelecidos em lei, aos seguintes requisitos:

I - aproveitamento racional e adequado;

II - utilização adequada dos recursos naturais disponíveis e preservação do meio ambiente;

III - observância das disposições que regulam as relações de trabalho;

IV - exploração que favoreça o bem-estar dos proprietários e dos trabalhadores.

Além disso, conforme apontado durante a roda, a sociedade critica os assentados, alegando que eles são pessoas preguiçosas, verdadeiros bandidos, que, ao invés de trabalharem para comprarem sua terra, querem roubar a de outros. Porém, o que passa despercebido é que a propriedade advinda da reforma agrária não é de graça, é paga. Nada na reforma agrária é dado, tudo é conquistado. O fornecimento da terra é só o começo de tudo.

Quando um assentamento é conquistado ele não possui estrutura, nem ao menos possui água, relatou uma participante. É cobrado do assentamento produtividade, mas ao mesmo tempo, não é fornecido nenhum meio para as pessoas produzirem, o acesso ao crédito rural é raro e quando ocorre não é suficiente para garantir o sucesso do lugar.

Um relato chamou atenção da equipe mediadora da roda, exposto por um agrônomo nascido em um grande latifúndio ( $25 \mathrm{mil} \mathrm{ha)} \mathrm{que} \mathrm{foi} \mathrm{doado} \mathrm{à} \mathrm{sua} \mathrm{família} \mathrm{pela} \mathrm{Igreja.} \mathrm{Ele} \mathrm{conta} \mathrm{que}$ após uma ação da reforma agrária a terra foi dividida e, a partir daí, com a vivência constatou que a reforma agrária foi ignorada ao longo dos tempos, ela é programada para não dar certo. O assentado recebe uma carga muito grande, pois, a reforma agrária não garante todas as condições para ele. Os trabalhadores rurais quando ficam doentes, não recebem nenhum auxílio, são abandonados em suas terras.

Um dos grandes desafios dos pequenos produtores rurais é a soberania alimentar do agronegócio, que frente às dificuldades enfrentadas nos assentamentos oferecem propostas para comprarem as terras, e os assentados que não têm mais alternativas, acabam cedendo e abrem mão de suas terras. Em contrapartida, atualmente muitos assentamentos se fortalecem pela agroecologia, visto que o cuidado especial com os alimentos gera uma maior relação entre o campo e a cidade. A criação de cooperativas também gera resultados positivos na prosperidade dos assentamentos. 


\section{CONSIDERAÇÕES FINAIS}

O projeto DATALUTA articula ensino, pesquisa e extensão no bojo de suas atividades. A coleta e registro diário dos dados da luta pela terra divulgados pela imprensa jornalística e órgãos do governo promovem o diálogo entre ensino e extensão, sobretudo no processo de aprendizado e atualização entre docentes e discentes sobre a questão agrária brasileira, fazendo-os refletir sobre a conjuntura atual do campo.

Mesmo com muitas dificuldades e resistências diante do momento político e da crise institucional brasileira dos últimos anos, a reforma agrária teve grandes revoluções e transformações. A pesquisa é a esperança de gerar uma imagem melhor dos assentamentos, pois é com projetos como o DATALUTA que a população tem a oportunidade de conhecer e desmistificar os preconceitos sobre a realidade da reforma agrária.

A interação com os estudantes externos e da UFU e com os movimentos socioterritoriais também propiciou uma aproximação das atividades de ensino, pesquisa e extensão, democratizando o acesso aos dados e estudos realizados pelos grupos de pesquisas por meio de eventos (Oficinas, Palestras, Jornadas, etc.), momento em que a comunidade é convidada para ser sujeito das decisões e discussões sobre a reforma agrária no país. Em especial, cabe destacar também a relevância da Jornada Universitária em Defesa da Reforma Agrária como possibilidade de apoio e reafirmação dos direitos dos trabalhadores do campo, estes que constantemente estão em luta e por vezes são criminalizados quando pouco se conhece desta realidade.

Por fim, a Roda de Conversa idealizada e realizada como um coletivo de práticas e saberes se configurou como uma importante ferramenta de diálogo e trocas de experiências, possibilitando desconstruir e repensar conceitos acerca do espaço agrário e seus desdobramentos, especialmente no contexto da questão agrária do estado de Minas Gerais.

\section{REFERÊNCIAS}

BRASIL. Constituição de 1988. Constituição da República Federativa do Brasil. Brasília, DF: Senado Federal, 1988.

CHAYANOV, A. V. La organización de la unidad económica campesina. Buenos Aires: Nueva Visión, 1974. 
CLEPS JÚNIOR, J. As ações de movimentos sociais no campo em 2010. In: CANUTO, A.; LUZ, C. R. S.; WICHINIESKI, I. (org.). Conflitos no Campo Brasil 2010. Goiânia: CPT, 2011. p. 136-143.

CLEPS JÚNIOR, J. Questão agrária, estado e territórios em disputa: os enfoques sobre o agronegócio e a natureza dos conflitos no campo brasileiro. In: SAQUET, M. A; SANTOS, R. A. dos (org.). Geografia agrária, território e desenvolvimento. São Paulo: Expressão Popular, 2010. p. 35-54.

DATALUTA. Relatório Brasil 2017. Presidente Prudente: NERA-UNESP, 2018. Disponível em: http://www2.fct.unesp.br/nera/relatoriosbr.php. Acesso em: 15 fev. 2019.

DATALUTA. Relatório Minas Gerais 2017. Uberlândia: LAGEA-UFU, 2018. Disponível em http://www.lagea.ig.ufu.br/relatoriosdatalutaminas.html. Acesso em 15 fev. 2019.

FELÍCIO, M. J. contribuição ao debate paradigmático da questão agrária e do capitalismo agrário. 2011. 214 f. (Doutorado em Geografia) - Faculdade de Ciências e Tecnologia, Universidade Estadual Paulista, Presidente Prudente, 2011.

FERNANDES, B. M. Questão agrária: conflitualidade e desenvolvimento territorial. In: BUAINAIN, A. M. (org.). Luta pela terra, reforma agrária e gestão de conflitos no Brasil. Campinas: Editora da Unicamp, 2005.

KAUTSKY, K. A questão agrária. Tradução de C. Iperoig. São Paulo: Proposta Editorial, 1980.

MOURA, D. J.; VICTOR, F. B.; CLEPS JÚNIOR, J. Jornada Universitária em Defesa da Reforma Agrária: Massacre de Felisburgo, Minas Gerais. Boletim Dataluta, Presidente Prudente, n. 90, jun. 2015.

MST. Universitários de todo país participam da Jornada Universitária em Defesa da Reforma Agrária. Disponível em: http://www.mst.org.br/2018/04/18/universitarios-de-todopais-participam-da-jornada-universitaria-em-defesa-da-reforma-agraria.html. Acesso em: 20 out. 2019.

OLIVEIRA, A. U. Modo de produção capitalista, agricultura e Reforma Agrária. São Paulo: Labur Edições, 2007. Disponível em: http://www.fflch.usp.br/dg/gesp. Acesso em: 19 jan. 2020.

PORTO-GONÇALVES, C. W. A geografia da riqueza, fome e meio ambiente. In: OLIVEIRA, A. U.; MARQUES, M. I. (org.). O campo no século XXI. São Paulo: Casa Amarela; Paz e Terra, 2004. p. 207-253.

RAFFESTIN, C. Por uma geografia do poder. São Paulo: Ática, 1993.

SAUER, S. Terra e modernidade: a reinvenção do campo brasileiro. São Paulo: Expressão Popular, 2010. 